\title{
Violência, gênero e poder na literatura de Assia Djebar e Leïla Sebbar
}

\author{
Vera Lucia Soares
}

\begin{abstract}
Os atos de violência não dependem da vontade de um líder individual, por mais carismático que seja, nem da estrutura de uma única organização, da existência de um país ou do fanatismo de uma única religião com crentes alimentados pela perspectiva de uma vida gloriosa após a morte. A violência, infelizmente, é sistemática. Ela assume várias formas em diferentes partes do globo.
\end{abstract}

Tariq Ali

A veiculação pela mídia globalizada de imagens de violência praticada pelos povos árabes e/ou seguidores dos islamismo em todo o mundo é uma recorrência nos últimos tempos. Violência contra países do Ocidente, mulheres, intelectuais, grupos étnicos, religiosos e outros. Mas qual seria o sentido de tanta violência? Fanatismo religioso? Luta pelo poder? Questão de mentalidade?

Já há bastante tempo intelectuais de várias áreas do conhecimento vinham se debruçando sobre essa questão, mas os debates se intensificaram a partir dos atentados de 11 de setembro de 2001 nos Estados Unidos que se tornaram símbolo maior da violência árabe-islâmica contra o Ocidente.

Não é de hoje que os árabes-muçulmanos são vistos pelo mundo ocidental como povos bárbaros, fanáticos e extremamente violentos. Edward Said, em seu estudo sobre o orientalismo ${ }^{*}$, mostra, no entanto, que o Oriente tal como o concebemos é uma invenção do Ocidente e que essas imagens foram sendo construídas e reconstruídas ao longo dos tempos.

Ainda na Idade Média, a Europa se viu impelida a lidar com uma forma de vida totalmente nova - o islã - que aparecia como uma versão fraudulenta do cristianismo, provocando um certo temor. Temor que, para Said, era justificado porque, após a morte de Maomé em 632, a hegemonia militar, cultural e

- (Said, Edward W. Orientalismo: o Oriente como inven cão do Ocidente. Trad. Tomás Rosa Bueno. São Paulo: Companhia das Letras, 1990.) 
religiosa do islã cresceu enormemente. Com isso, o islã passou a "simbolizar o terror, a devastação, o demoníaco, as hordas de odiosos bárbaros ${ }^{\prime *}$, enfim um perigo para o conjunto da civilização cristã.

A partir do século XVIII, com a invasão do Egito por Napoleão, que projetava transformar essa terra de obscuridade e barbárie em um departamento de erudição francesa, e, mais tarde, com a expansão colonial européia na Ásia e na África que se estendeu do século XIX a meados do XX, o Oriente vai ser reconstruído e remoldado pelos orientalistas europeus. Era preciso "aproximar o Oriente da Europa, para depois absorvêlo inteiramente e cancelar, ou pelo menos baixar o tom e reduzir a sua estranheza e, no caso do islã, a sua hostilidade ${ }^{\prime \prime^{*}} .0$ Oriente desperta também o interesse de vários escritores do século XIX, entre os quais os franceses Chateaubriand, Lamartine, Flaubert, Nerval. Mas, apesar das diferenças de estilo, o Oriente visto por esses autores se caracteriza basicamente pela excentricidade, pelo exotismo, pelo atraso, pela feminina penetrabilidade, enfim, como "um lugar que precisava da atenção, da reconstrução e até mesmo da redenção ocidental ${ }^{\prime \prime *}$. Aliás, foi esse ideal humanitário que permeou a política expansionista colonial francesa no século XIX.

No entanto, quando esses povos começam a lutar contra a ocupação colonial, quando o anticolonialismo unifica todo o mundo oriental, os europeus vêem nessa atitude um insulto à democracia ocidental. Os antigos estereótipos do Oriente bárbaro, violento e fanático são, então, retomados.

Depois da Segunda Guerra, os Estados Unidos tomam o lugar da Europa, tornando-se o centro da política mundial e, conseqüentemente, vão construir a sua representação do Oriente islâmico. Tendo em vista os constantes atritos entre árabesmuçulmanos e judeus, "o árabe passa a ser concebido como uma sombra que persegue o judeu" ${ }^{\prime *}$. Além disso, a partir de 1973, com o boicote do petróleo impetrado pelos países árabes fornecedores do produto, esses orientais são novamente vistos como uma ameaça ao mundo ocidental.

Com o avanço do capitalismo e dos meios eletrônicos de comunicação mediados prioritariamente pelos Estados Unidos, acentua-se um processo de ocidentalização do mundo, pois, como bem critica Stuart Hall, embora a globalização seja por definição algo que afeta o globo inteiro, ela é essencialmente 
um fenômeno ocidental. Isto porque "são as imagens, os artefatos e as identidades da modernidade ocidental, produzidos pelas indústrias culturais das sociedades 'ocidentais' (incluindo o Japão) que dominam as redes globais ${ }^{\prime \prime *}$. Assim, a mídia globalizada força a informação para dentro de moldes padronizados onde - Oriente aparece cada vez mais estereotipado. Nos filmes, na televisão, na imprensa escrita, os árabes são geralmente mostrados em grandes números; as imagens apresentam massas enraivecidas, gestos irracionais e excêntricos. E, por trás dessas imagens - diz Edward Said -, "está a ameaça da jihad. Resultado: um temor de que os muçulmanos (árabes) tomem conta do mundo" ${ }^{\prime *}$.

Esse temor é reforçado pelo crescimento, a partir da Revolução Iraniana, de movimentos islâmicos fundamentalistas em alguns países muçulmanos do Oriente Médio, cujo principal objetivo é criar estados religiosos nos quais os princípios políticos de organização estejam alinhados com as leis do Alcorão, ou melhor, com a sua interpretação mais radical estabelecida pelo direito canônico islâmico, a Charia. Tais movimentos visam, na verdade, ao poder. Diabolizando tudo o que venha do ocidente - daí a hostilidade ao imperialismo americano - e usando a religião como força política e ideológica mobilizadora e unificadora, se estabelecem e agem sobretudo em estados onde proliferam crises econômicas, sociais e identitárias. Entre eles, estão, por exemplo, o Al-Qaeda de Osama Ben Laden, que apoiou o regime talibã do Afeganistão e foi responsabilizado pelos atentados de 11 de setembro de 2001 nos Estados Unidos, a Jihad Islâmica na Palestina, cujos atentados suicidas contra os israelenses vêm ocupando a mídia nos últimos tempos e o FIS ( Front Islamique du Salut) na Argélia que, desde a anulação das eleições legislativas de 1991, em que obtivera a maioria dos votos, lançou o país em uma guerra civil não declarada.

Na luta pelo poder, esses grupos fazem alvo de seus ataques não apenas os militares ou políticos que se interpõem em seu caminho, mas também todos os defensores ou propagandistas de idéias e valores exportados do Ocidente que, segundo eles, atentam contra a lei canônica do islã, a Charia. Na Argélia, por exemplo, o número de assassinatos cometidos pelo FIS contra intelectuais, escritores, jornalistas e mesmo contra homens e mulheres do povo que, de uma forma ou de outra, reivindicavam a liberdade de ação e de expressão atingiu cifras exorbitantes na década de 1990.
* (Hall, Stuart. A identidade cultural na pós-modernidade. Trad. Tomaz Tadeu da Silva e Guacira Lopes Louro. 5. ed. Rio de Janeiro: DP\&A, 2001: 79.)

(Said, Edward W. Orientalismo: o Oriente como invenção do Ocidente. Op. cit.: 291.) 
(Robin, Régine. Le roman mémoriel: de l'histoire à l'écriture du hors-lieu. Montreal: Préambule, 1989: 67.)

(Hall, Stuart. A identidade cultural na pós-modernidade. Op. cit.: 89.)

(Scott, Joan. "Genre: une catégorie utile d'analyse historique". Trad. Elen Varikas. Les Cahiers du GRIF, n. 37-38. Paris, 1988: 125-53.)

(Djebar, Assia. "Oran, langue morte". Em: Oran, langue morte. Arles: Actes Sud, 1997: 11-48.)
Muitos intelectuais árabes e ou muçulmanos perseguidos ou condenados à morte em seus países pelos fundamentalistas emigram para a Europa ou para os Estados Unidos, juntandose a outros que, por razões várias, há muito vivem no exterior, como o crítico palestino Edward Said acima citado.

Mas, enquanto os críticos da diáspora árabe-muçulmana interpretam os discursos e analisam os fatos, os escritores nos dão, através de seus textos literários, um testemunho da vivência, permitindo, assim, o desvelamento do que Régine Robin chama de "zonas de sombra da memória" ${ }^{\prime *}$. É o que fazem, por exemplo, Assia Djebar e Leïla Sebbar, escritoras argelinas de origem árabe-muçulmana radicadas na França e autoras das duas novelas que compõem o corpus deste trabalho.

Vivendo no entre-dois, ou seja, entre o Oriente e o Ocidente, essas escritoras são obrigadas "a habitar duas identidades, a falar duas linguagens culturais, a traduzir e a negociar entre elas $^{\prime \prime *}$. É, portanto, desse entre-lugar que elas produzem uma literatura de caráter eminentemente político, transformando sua escritura em voz coletiva, voz que se propõe a desvelar as formas de violência que marcaram e marcam as relações entre Oriente e Ocidente (no caso específico, entre Argélia e França), colonizadores e colonizados, homens e mulheres. Relações que põem em evidência a ligação intrínseca entre gênero e poder, sobretudo quando se trata de regimes autoritários, nos quais conforme análise de Joan Scott - os dirigentes legitimam a dominação, a força, a autoridade central e o poder soberano identificando-os ao masculino, enquanto o inimigo, a subversão e a fraqueza são identificados ao feminino*.

Assia Djebar, escritora argelina vivendo na França desde a década de 1970 e trabalhando atualmente nos Estados Unidos como professora visitante da Universidade de Nova York, nos faz transitar, através de seus textos literários, por diferentes períodos da história da Argélia marcados pela violência e pela luta pelo poder.

Na novela Oran, langue morte*, Assia Djebar se utiliza do recurso epistolar para traduzir, de forma mais intimista, os traumas vivenciados por uma argelina por conta da violência que em dois momentos distintos da história marcaram sua cidade natal, Oran. Nessa longa carta à amiga Olivia, que está na França, a narradora (que não é nomeada) conta sua volta a Oran, depois de 33 anos de exílio em Paris, para acompanhar a 
tia que a criara em seus últimos dias de vida. Mas esta volta é, na verdade, um retorno ao passado, à sua origem da qual precisa fazer o luto, ou seja, se libertar. E nesse passado está o assassinato de seus pais, quando ela tinha apenas dez anos de idade, pelos extremistas franceses durante a guerra da Argélia.

Militante pela independência do país e perseguido pelo exército francês, esse casal tinha conseguido fugir para a França, onde continuou sua militância clandestina por alguns anos, enquanto a filha permanecera na Argélia aos cuidados de uma tia materna. Caindo doente, o pai insiste junto à mulher para voltarem a Oran, o que acontece em 1960. Durante um tempo, conseguem sobreviver com a ajuda da família e dos amigos, até que, devido a uma hemorragia, o pai é internado. A mulher e uma vizinha o acompanham ao hospital, palco do frio assassinato do casal diante dessa amiga, que se encarregará de reportar o acontecido à família. Assassinato que, por sua vez, é agora recriado pela narradora na carta que escreve à amiga:

Nisto eles entraram: eles, um grupo de médicos; novatos? Em todo caso, desconhecidos. Três, eles são três e usam jaleco branco.

Um deles se mantém de pé, perto da porta. 0 segundo, com uma voz dura, interpela o doente:

- É você mesmo que é chamado de...?

Minha mãe interrompe:

- Eu sou a mulher dele! 0 quê que os senhores desejam?

Mamãe não tem tempo de continuar.

0 terceiro, mais à frente, tira um fuzil de debaixo do jaleco. Calmamente, enquanto os outros dois bloqueiam a saída, esvazia a arma sobre o doente. Já o terceiro, com um revólver na mão, visa ao corpo em pé de mamãe que se desloca.

[...]

Eles saem recuando, os três: eles, os falsos médicos, os assassinos.
Sur ce, ils entrèrent: eux, un groupe de médecins; des nouveaux? En tout cas, des inconnus. Trois, ils sont trois et en blouse blanche.

L'un se tient debout, près de la porte. Le second, $d^{\prime}$ une voix rude, interpelle le malade.

- Vous êtes bien le dénommé...?

Ma mère intervient:

- Je suis sa femme! Que voulez-vous?

Elle n'a pas eu le temps de continuer, Maman.

Le troisième, le plus en avant, de dessous sa blouse, sort un fusil. Posément, pendant que les deux autres bloquent I'issue, il vide son arme sur le malade. Tandis que le second, un revolver à la main, vise le corps debout de Maman qui se disloque.

[...]

Ils sortent tous les trois à reculons: eux, les faux médecins, les meurtriers. ${ }^{*}$ 
- "- Sa soeur... elle veut voir sa soeur blessée!" (lbid.: 38.)

* “- Puisque toi, la petite, tu sais parler français, alors tu peux ajouter 'madame'? On ne t'a pas appris à l'école, non?" (Ibid.: 39.)

(Chartier, Roger. "Diferença entre os sexos e dominação simbólica". Trad. Sheila Schvarzman. Cader nos Pagu, n. 4. Campinas, UNICAMP, 1995: 40.)

(Robin, Régine. Le deuil de l'origine: une langue en trop, la langue en moins. Paris: Presses Universitaires de Vincennes, 1993.)
Além dessa violência física contra os pais, seu relato também dá contra de outro tipo de violência por ela vivenciado quando acompanha a tia ao hospital para tentar obter notícias da mãe, que pensam ainda estar viva. Como a tia não domina a língua francesa, a menina traduz sua pergunta para a enfermeira chefe: "- Sua irmã... ela quer ver sua irmã ferida!" ajudar, a francesa retruca em tom reprovador e irônico: "- Menina, já que você sabe falar francês, poderia acrescentar 'madame'? Não the ensinaram na escola, não ${ }^{\prime \prime}{ }^{*}$. Na verdade, a enfermeira se utiliza aqui do discurso masculino do colonizador por ela incorporado para impor sua autoridade, atitude representativa do que Roger Chartier chama de "violência simbólica", cuja raiz está na "interiorização, pelas mulheres, de normas enunciadas pelos discursos masculinos ${ }^{\prime \prime *}$. Essa violência marca profundamente a menina, que diz ter sentido a palavra "madame" vibrar dentro dela como o início de uma provação. Realmente, logo em seguida, Ihe dão a notícia de que sua mãe também tinha morrido.

Com a reconstrução, por meio da escritura, dessas cenas ligadas à morte de seus pais, a narradora se liberta, de certa forma, desse seu passado de violência, ou, como diria Régine Robin, faz o "luto da origem" ${ }^{\prime *}$. Mas enquanto escreve, ela diz sentir-se novamente sobressaltada por gritos e prantos. São, na verdade, os ecos da violência que impera hoje em Oran, vítima agora de outros assassinos, não mais os extremistas franceses da época colonial, mas os militantes do FIS que, na luta cega pelo poder, atacam seus próprios irmãos argelinos que questionam seus preceitos radicais e defendem idéias liberais. Esta nova onda de violência que assola a cidade lhe é confirmada no dia do enterro de sua tia, quando toma conhecimento do assassinato, por um grupo de jovens militantes do FIS, de um professor universitário que durante toda a sua vida se dedicara à formação intelectual das novas gerações.

Assim, o presente e o passado dessa cidade argelina se confundem e se entrelaçam na narrativa de Assia Djebar pelo viés da violência. Violência constante na história da Argélia, ontem praticada pelo Ocidente colonizador, hoje por seus próprios filhos muçulmanos. Violência fruto de lutas políticas pelo poder onde os que pretendem dominar tentam por todos os meios subjugar o inimigo, que, nesta novela, é representado por ho- 
mens, mulheres e crianças comuns que, em um dado momento, lutaram por algum tipo de liberdade.

Inconformada e já sabendo a priori a continuação dessa história de violência, a narradora termina a carta à amiga anunciando sua partida de Oran, sua volta definitiva à França por não querer ver nem dizer nada mais sobre o presente dessa cidade, apenas escrever:

Parto porque não quero ver mais nada, Olivia. Dizer nada mais: apenas escrever. Escrever Oran no vazio, em uma língua muda, entregue enfim ao silêncio.

Escrever Oran minha língua morta.
Je pars car je ne veux plus rien voir, Olivia. Ne plus rien dire: seulement écrire. Écrire Oran en creux dans une langue muette, rendue enfin au silence.

Écrire Oran ma langue morte."

(Djebar, Assia. "Oran, langue morte". Op. cit.: 48.)

Este é um dos desafios, senão o maior, que vem sendo enfrentado por essas escritoras da diáspora árabe e/ou muçulmana: escrever na língua do exílio o silêncio que assola seu país, fazer aflorar na língua estrangeira, que também é sua, os ecos da língua de origem, o árabe, emudecida pela violência da censura. Escritura que se transforma também em ato simbólico de violência. Escritura da violência, violência da escritura, pois é através dela que essas escritoras desvelam as zonas sombrias da memória argelina.

Também Leïla Sebbar, outra argelina radicada na França, faz da escritura o espaço de expressão de uma memória de violência. A novela La photo d'identité tem como eixo narrativo uma foto exposta na vitrine de uma livraria em Paris que chama a atenção, ao mesmo tempo, de um homem e de um menino filho de imigrantes argelinos.

Trata-se da foto de uma mulher argelina tomada durante a guerra pela independência do país. 0 menino sente-se atraído pelo retrato porque essa guerra o interessa e seus pais se negam a falar sobre 0 assunto, como se temessem reavivar a chama de um passado silenciado, escondido no fundo da memória por razões desconhecidas. Além disso, a mulher da foto lhe faz lembrar a mãe quando esta se veste para as festas de família com roupas típicas de sua região. Na verdade, o menino busca nessa imagem vestígios de sua origem e da própria memória da Argélia. Quanto ao homem, este quer liberar a memória (a razão) de sua mãe, que acredita estar presa nessa foto.

(Sebbar, Leïla. "La photo d'identité". Em: La jeune fille au balcon. Paris: Seuil, 1996: 59-83.) 
Depois de vários dias observando o retrato na vitrine e sem trocar nenhuma palavra um com o outro, o menino e o homem entram na livraria. Segundo a proprietária, esta e outras fotos que constam de um álbum foram tiradas durante a ocupação francesa na Argélia para a confecção de carteiras de identidade. Enquanto folheiam o álbum, sentados lado a lado, 0 homem revela ao menino que está à procura do fotógrafo para matá-lo porque este roubara o espírito de sua mãe ao fotografála, conforme Ihe explicara a avó, fazendo-o prometer que procuraria este homem onde quer que estivesse para tomar-lhe a máquina e, assim, salvar a sua mãe. Esta é uma crença ligada à tradição muçulmana transmitida pelo profeta Maomé, segundo a qual está terminantemente proibido tentar capturar a imagem de Deus e, por conseguinte, de qualquer ser humano, pois este foi feito à sua imagem e semelhança.

Assim, submetendo-se à força da tradição e à vontade da avó, este homem transforma sua vida em uma busca incessante do fotógrafo que, finalmente, acredita ter encontrado ao ter nas mãos o retrato da mãe. E num gesto inesperado, mas decisivo, arranca a foto do álbum, observa-a longamente pela última vez, dobra-a várias vezes e a rasga em pedacinhos. Em seguida, vai até a lareira e joga os restos no fogo. Ao se retirar da livraria acompanhado do menino, volta-se para a proprietária e diz:

- Pronto, acabou. Matei o soldado fotógrafo e minha mãe poderá me reconhecer quando eu chegar a sua casa, na aldeia. Acabou. Adeus, minha senhora.
- Voilà, c'est fini.J'ai tué le soldat photographe et ma mère me reconnaîtra quand j'arriverai chez elle, au village. C'est fini. Au revoir, madame.*

Nesta novela, a violência é representada não tanto fisicamente, mas sobretudo de forma simbólica. Inicialmente, temos a violência cometida pelos franceses contra a tradição muçulmana, talvez por ignorar os signos culturais do outro ou, mais provavelmente, por considerá-los como marcas do atraso e da inferioridade dessa cultura. Mas trata-se também de uma violência contra as mulheres dessa aldeia, que foram forçadas a se submeter às ordens dos oficiais franceses, conforme as palavras da avó retomadas pelo homem ao relatar sua história ao menino: Nesta aldeia [...], chegaram soldados para nos vigiar, eles fizeram papéis para nos controlar, homens e mulheres. Uma manhã,
Dans ce village $[. .$.$] , des soldats sont$ venus pour nous surveiller, ils ont fait des papiers pour nous contrôler, hommes et femmes. Un matin, 
obrigaram as mulheres jovens e velhas a deixar suas casas e, em plena praça, o soldado fotógrafo começou seu trabalho. 0 chefe mandou as mulheres tirarem os lenços, as velhas não quiseram, ele não insistiu. [...] Elas não entendiam o que estava acontecendo, mas eu entendi depois, quando a cabeça de sua mãe se esvaziou. Sua mãe era linda, a mulher mais linda da aldeia. Ela tinha se escondido, mas os soldados a encontraram, eles não bateram nela, mas a arrastaram até o banco encostado no muro branco... ils ont obligé les femmes, jeunes et vieilles à quitter les maisons, et, sur la place, le soldat photographe s'est mis au travail. Le chef a ordonné aux femmes d'enlever leurs foulards, les vieilles n'ont pas voulu, il n'a pas insisté. [...] Elles ne comprenaient pas ce qui se passait, moi j'ai compris après, quand la tête de ta mère s'est vidée. Ta mère était belle, la plus belle femme du village. Elle s'était cachée, mais les soldats I'ont trouvée, ils ne l'ont pas battue, mais ils I'ont traînée jusqu'au banc contre le mur blanc...*
(Ibid.: 79-80.)

Da mesma forma, a dominação da avó sobre o neto, obrigandoo a sacrificar sua juventude por conta dessa mesma tradição violada pelos franceses, pode ser lida como uma representação da "violência simbólica" definida por Roger Chartier e à qual já me referi. Segundo ele, as representações da inferioridade feminina, incansavelmente repetidas e mostradas nos discursos e nas práticas, acabam inscrevendo-se nos pensamentos e corpos de umas e de outros. Mas - adverte o historiador - "uma tal incorporação da dominação não exclui afastamentos e manipulações". São eles que vão permitir o deslocamento ou a subversão da relação de dominação. A reapropriação pelo dominado de uma representação imposta se volta muitas vezes contra a ordem dominante que a produziu* .

Tendo, portanto, incorporado um papel que lhe foi determinado pela comunidade islâmica, o de guardiã das tradições, e valendo-se do poder que a idade garante à mulher muçulmana no espaço privado, a avó reverte a relação habitual de dominação do masculino sobre o feminino. Assim, ela mobiliza para seus próprios fins esse papel que a religião e a sociedade lhe inculcaram e subjuga o neto, ou seja, o masculino, obrigando-o, por sua vez, a destruir uma outra representação do masculino, o colonizador francês que dominara a sua gente. Desta forma, ao rasgar e queimar o retrato da mãe tirado pelo fotógrafo francês, esse homem que representa o argelino colonizado, fraco, submisso e, logo, identificado ao feminino considera ter eliminado, ainda que simbolicamente, o antigo colonizador.

(Chartier, Roger. "Diferença entre os sexos e dominação simbólica". Op. cit.: 37-47.) 
(Sibony, Daniel. Entre deux: l'origine en partage. Paris: Seuil, 1991: 20.)

- (Glissant, Edouard. Introduction à une poétique $d u d i-$ vers. Paris: Gallimard, 1996.)
Como se vê, há nesta novela de Leïla Sebbar uma dupla reversão da relação de dominação em que o dominado ou o feminino se apropria de uma representação imposta e a reutiliza contra aquele que a produziu.

Por outro lado, o gesto desse homem de destruir o retrato amaldiçoado de sua mãe pode também ser lido como uma forma simbólica de fazer o luto de uma origem marcada pela violência. Daniel Sibony considera que todo exilado ou imigrante precisa fazer a "viagem da origem", mas não para ficar, e sim para poder partir e não ter mais que voltar compulsivamente*. Libertando-se do peso do passado, ou seja, tendo-Ihe dado um fim provisório, o ser diaspórico pode finalmente estabelecer laços mais fortes com a outra cultura em que está inserido no seu momento presente. Logo, fazer o luto da origem não significa abdicar dessa raiz, mas fazer dela uma raiz primeira que vai ao encontro de outras raízes, ou seja, optar pela identidade rizoma*. Mas este é um processo complexo, de muitas idas e vindas, de negociações contínuas entre as diferentes culturas postas em relação.

Assia Djebar e Leïla Sebbar, escritoras da diáspora argelina, fazem de sua escritura o espaço maior de expressão desse ir e vir, dessa negociação entre as duas culturas que as habitam: a cultura árabe-muçulma de origem e a cultura francesa de adoção. Nas duas novelas, acima analisadas, as personagens por elas criadas fazem, cada qual à sua maneira, o luto da origem, condição necessária para poderem ir ao encontro do outro: a narradora de Oran, langue morte se liberta do seu passado através da carta que escreve a uma amiga, já a personagem de La photo d'identité o faz destruindo a foto que o simbolizava. Mas, nos dois textos, o processo de volta à origem desvela diferentes imagens de violência que marcaram e marcam a memória e o imaginário do argelino. E a leitura das representações da violência nas duas novelas permitiu verificar que esta se dá sempre no espaço intersticial de dois pólos: Ocidente / Oriente, colonizador / colonizado, masculino / feminino. Conclui-se, então, que a violência é de parte a parte, mas ela tende mais para um lado do que para outro conforme a situação ocupada em um dado momento por cada um dos pólos, ou seja, se a de dominador / masculino ou se a de dominado / feminino.

Por outro lado, os textos em questão também deixam ver que, muitas vezes, o ser dominado ou feminino, tendo interio- 
rizado as representações de inferioridade que the foram impostas, se apropria das mesmas e as reverte contra seus dominadores, o que comprova, pelo menos no plano literário, que a violência, longe de ser prioridade do Oriente, como pretende a mídia globalizada de hoje, se revela uma estratégia de força utilizada na luta pelo poder, onde haverá sempre um que domina identificado ao masculino e outro que é dominado e, logo, feminino.

Assim, ao pôr a nu essa relação intrínseca entre violência, gênero e poder, as novelas de Assia Djebar e Leïla Sebbar desconstroem as imagens de barbárie, atraso e fanatismo religioso atribuídas pelo Ocidente ao mundo árabe-muçulmano e nos levam a perceber que se trata, na verdade, de uma luta de poder entre dois pólos. 


\section{Vera Lucia Soares}

Doutora em História Social pela Universidade Federal Fluminense e Professora Adjunta de Língua Francesa e Literaturas Francófonas na mesma universidade. É autora do livro Escritura dos silêncios: Assia Djebar e o discurso do colonizado no feminino (Niterói: EdUFF, 1998) e tem vários artigos publicados, entre os quais "Silences dévoilés: femme, histoire et politique dans I'ecriture d'Assia Djebar" (Em: Bonn, C.; Redouane, N. \& Benayoun-Szmidt, Y. (orgs.). Algérie: nouvelles écritures. Paris: L'Harmattan, 2001) e "Reconstruindo a memória argelina: um diálogo entre a ficção e a história" (Gragoatá. Revista do Programa de Pós-Graduação em Letras da UFF, n. 6. Niterói, EdUFF, 1999).

Palavras-chave

gênero

literatura

poder

representação

violência

Keywords

gender

literature

power

representation violence

Recebido em 26/7/2002

Aprovado em 20/11/2002

\section{Resumo}

Este artigo estuda as representações da relação entre violência, gênero e poder na escrita literária de Assia Djebar e Leïla Sebbar, que desconstroem a imagem de fanatismo e barbárie que o Ocidente faz do Oriente árabe-muçulmano.

\section{Abstract}

This paper deals with the representations of the relationship between violence, gender and power in Assia Djebar's and Leïla Sebbar' s literary discourse which deconstruct the image of fanaticism and barbarity that the West makes of the Arabian-Moslem East.

\section{Résumé}

Cet article fait une étude des représentations de la relation entre violence, genre et pouvoir dans I'écriture d'Assia Djebar et de Leïla Sebbar déconstruisant I'image de fanatisme et de barbarie que I'Occident se fait de l'Orient arabe-musulman. 